OPEN ACCESS

Edited by:

Selena Ahmed,

Montana State University,

United States

Reviewed by:

Tânia Gonçalves Albuquerque, Instituto Nacional de Saúde Doutor

Ricardo Jorge (INSA), Portugal

Youssef Aboussaleh,

Ibn Tofail University, Morocco

${ }^{*}$ Correspondence:

Irana W. Hawkins

irana.hawkins@mail.waldenu.edu

Specialty section:

This article was submitted to Nutrition and Sustainable Diets,

a section of the journal

Frontiers in Nutrition

Received: 12 March 2019

Accepted: 25 July 2019

Published: 14 August 2019

Citation:

Hawkins IW, Mangels AR, Goldman R and Wood RJ (2019) Dietetics

Program Directors in the

United States Support Teaching

Vegetarian and Vegan Nutrition and Half Connect Vegetarian and Vegan Diets to Environmental Impact.

Front. Nutr. 6:123.

doi: 10.3389/fnut.2019.00123

\section{Dietetics Program Directors in the United States Support Teaching Vegetarian and Vegan Nutrition and Half Connect Vegetarian and Vegan Diets to Environmental Impact}

\author{
Irana W. Hawkins ${ }^{1,2 *}$, A. Reed Mangels ${ }^{1}$, Robert Goldman ${ }^{3}$ and Richard J. Wood ${ }^{1}$ \\ ${ }^{1}$ Department of Nutrition, University of Massachusetts Amherst, Amherst, MA, United States, ${ }^{2}$ Doctoral Programs in Public \\ Health, School of Health Sciences, Walden University, Minneapolis, MN, United States, ${ }^{3}$ Math and Computational Sciences, \\ Simmons University, Boston, MA, United States
}

Registered Dietitian Nutritionists (RDNs) are clinicians trained in the application of food, nutrition, and dietetics. Vegetarians and vegans have a lower risk of many nutrition-related chronic diseases that are epidemic while vegetarian and vegan diets are associated with reduced environmental impact. Despite this strong diet-disease and diet-environment connection, it is not known if dietetics students are taught the principles of vegetarian and vegan nutrition. The overarching goal of our study was to investigate curricular practices in accredited dietetics training programs in the United States (U.S.) including (1) the prevalence and perceived importance of vegetarian and vegan nutrition instruction and (2) if program directors connect vegetarian and vegan diets to climate change mitigation and resource conservation. Primary data were collected by way of a cross-sectional, Internet-based survey. All Accreditation Council for Education in Nutrition and Dietetics (ACEND) program directors in the U.S. $(N=574)$ were sent a 37-question survey and invited to participate in the study. Outcome measures included the prevalence of vegetarian and vegan nutrition instruction, quantifying if relationships exist among variables, and the frequency of connecting vegetarian and vegan diets to environmental impact. Descriptive and inferential statistics were utilized. Respondents $(n=205)$ indicated that over $51 \%$ of programs teach vegetarian nutrition while $49 \%$ teach vegan nutrition. There were significant differences between program type and the prevalence of vegetarian $(p=0.00005)$ and vegan $(p=0.00005)$ nutrition instruction. Over $90 \%$ of program directors believe that vegetarian and vegan nutrition should be taught. Over $50 \%$ of programs identify the connection between vegetarian and vegan diets in climate change mitigation and resource conservation. Most ACEND program directors believe vegetarian and vegan nutrition should be taught and half connect diet to environmental concern. Nevertheless, there is a discrepancy between beliefs and practice behaviors. These results suggest the need for increased collaboration and the use of novel techniques that better incorporate vegan and vegetarian nutrition throughout dietetics education.

Keywords: vegetarian nutrition, vegan nutrition, dietetics education, dietetics practice, plant-based nutrition 


\section{INTRODUCTION}

Many of the leading causes of mortality in the U.S. are dietrelated, with heart disease the number one killer and cancer, stroke, and diabetes among the top seven causes of mortality ( 1 , 2). More than two-thirds of adults in the U.S. are overweight or obese (3). Almost $20 \%$ of children and adolescents in the U.S. are obese; almost $6 \%$ are classified as severely obese (4). Overweight and obesity are risk factors for heart disease, diabetes, high blood pressure, stroke, osteoarthritis, and certain cancers. Type 2 diabetes (T2D) is an epidemic with 1.5 million new cases per year in adults in the U.S. (5). In addition to overweight/obesity, risk factors for cancer include lack of physical activity and unhealthy dietary patterns including a high consumption of red or processed meats and a very low intake of whole grains, fiber, fruit and vegetables (6).

A growing body of literature demonstrates that vegetarians and vegans have a lower risk of many diet-related chronic diseases and that vegetarian and vegan diets are effective in the treatment of these diseases (7). Meta-analyses have shown that vegetarian diets can significantly lower blood pressure (8) and BMI (body mass index) (9). Additionally, vegetarians have a $29 \%$ lower mortality from ischemic heart disease (10) and an $8 \%$ lower risk of total cancer (9) compared to omnivores. In studies comparing different types of vegetarians and nonvegetarians, vegans have the lowest BMI (11), blood pressure (12), and prevalence of diabetes (11). Vegetarian diets have been successfully used to treat $\mathrm{T} 2 \mathrm{D}(13,14)$ and have significant benefits related to weight reduction compared to non-vegetarian diets (15). Additionally, components of vegetarian and vegan diets including phytonutrients (16), dietary nitrates (17), and dietary fiber (18) have demonstrated impressive beneficial health outcomes. Although the Academy of Nutrition and Dietetics encourages fiber intake from a wide variety of whole plant foods, only $5 \%$ of Americans achieve an adequate intake (18).

The 2015-2020 Dietary Guidelines for Americans recommends "a healthy vegetarian eating pattern" as one of three "healthy eating patterns that can be adapted based on cultural and personal preferences" (19). The position statement on vegetarian diets of the Academy of Nutrition and Dietetics (the world's largest organization of food and nutrition professionals) endorses appropriately planned vegetarian and vegan diets which are considered safe and appropriate for all stages of the lifecycle and recognizes their therapeutic role in chronic disease prevention and management (7). It is also important to underscore the data implicating meat in adverse health outcomes. The International Agency for Research on Cancer classified processed meat as carcinogenic to humans while red meat was classified as possibly carcinogenic (20). Epidemiological studies implicate red meat in diabetes risk as well as cardiovascular mortality $(21,22)$.

The Academy of Nutrition and Dietetics credentials Registered Dietitian Nutritionists (RDNs) and Nutrition and Dietetic Technicians, Registered (NDTRs) in the U.S through the Commission on Dietetic Registration (23). RDNs and NDTRs are the healthcare providers solely trained in the application of food, nutrition, and dietetics so to protect public health and promote well-being (24). The work of RDNs and NDTRs is interdisciplinary, spanning a multitude of career paths and disciplines that includes but is not limited to healthcare practice and healthcare administration; growing food, preserving food, and all aspects of agriculture that includes local, regional, and global food systems; technology and social media; research; urban planning; food security and global sustainable development; epidemiology and public health; planetary health and biodiversity; and education spanning from early care to higher education.

Despite the impressive evidenced-based data supporting vegetarian and vegan diets in chronic disease management and prevention, several studies suggest that dietetics practitioners may have knowledge deficits and lack confidence in the area of vegetarian and vegan nutrition. For example, 23\% of Missouri dietitians demonstrated knowledge deficits with regard to the statement "the only high quality proteins are animal proteins" (25). Half of dietitians surveyed in 2012 stated that animal products were essential for a healthy diet (25). Although more than $70 \%$ of Canadian healthcare providers including dietitians were aware that plant-based diets could be used to manage T2D, less than one-third recommended these diets (26). Hence, Bandura's constructs of self-efficacy may be particularly useful to dietitians in the realm of applying vegetarian and vegan nutrition in practice $(27,28)$. As Bandura explains, the processes of developing hands-on skills and mastery experiences, modeling the behaviors, increasing performance standards and minimizing anxiety when facing challenges or setbacks can build self-efficacy $(27,28)$. Self-efficacy was shown to be an important factor in dietitians leading the charge of environmental care (29) and was likely a factor for vegetarian and vegan dietitians that use diet as a climate change mitigation strategy (30).

As the proposed modern-day geological era known as the Anthropocene demonstrates, humans are altering the Earth System in ways that may altogether change the Earth system and its ability to support humanity (31). Steffen and colleagues delineate that if the current human-dominated trajectory of the "Hothouse Earth" does not shift toward a "Stabilized Earth" model, irreversible and dangerous outcomes may ensueespecially for those most vulnerable that have limited resources (31). Anthropogenic greenhouse gas emissions that drive increases in the Earth's surface temperatures are linked to our fossil-fuel based food and animal agriculture systems that have degraded the biosphere along with the constant and massive overuse of natural resources (32).

Furthermore, anthropogenic biodiversity loss and climate change negatively impact the Earth System and the planetary boundaries (33). In fact, Ceballos and colleagues stated that, "The loss of biological diversity is one of the most severe humancaused global environmental problems" (34). The May 6, 2019 press conference of the Intergovernmental Panel on Biodiversity and Ecosystem Services (IPBES) discussed highlights of first intergovernmental report on the global state of biodiversity where over 15,000 scientific publications were scrutinized (35). The IPBES scientists emphasized, "The scale of biodiversity loss is immense, and the sense of urgency indicates we have no time to 
waste. We need bold action and commitment from local to global levels" (36). Examples of such actions included thoughtful dietary choices (36).

An important body of literature delineates that wholesome plant-based diets including vegetarian and vegan diets can positively impact the natural environment (37-44). Acknowledging that food and agriculture is a major driver of both poor human health and environmental degradation, the recent EAT-Lancet Commission Report calls for a "Great Food Transformation" where food systems produce healthy diets from agricultural processes that nurture the planetary processes which are inextricably tied to human health (45). Their proposed "planetary health diet" emphasizes whole plant foods including fruits, vegetables, whole grains, nuts, and legumes which dominate the recommendations (46).

Dietetics professionals have long advocated for sustainable food systems $(47,48)$, minimizing food waste (49), supporting biodiversity $(48,50)$, creating resilient food and water systems (51), and using diet to mitigate climate change (30). Most dietitians surveyed (75\%) from a random sample of all credentialed dietitians in the U.S. believe climate change is an important issue (30). Dietitians have also sought to understand the feasibility of incorporating sustainable food systems education into dietetics education $(52,53)$ while some dietetics education programs emphasize sustainable food systems (54). Lastly, dietitians and other clinicians have been called upon to enact forward-thinking leadership to help individuals and communities protect planetary health with actions such as mindful food choices (55).

Because of (1) the burden of epidemic levels of obesity and $\mathrm{T} 2 \mathrm{D}$ and the therapeutic value of vegetarian and vegan diets in chronic disease prevention and management and the associated health care cost savings (40), (2) the urgency of mitigating the impact of food choices in breaching our planetary boundaries in order to maintain planetary health, and (3) the need to correct dietetics-based knowledge and practice deficits for those pursuing careers as RDNs and NDTRs, our research study was conceptualized. It is unclear if program directors of accredited dietetics education programs in the U.S. teach vegetarian and vegan nutrition or if they connect vegetarian and vegan diets to environmental conservation. Thus, the overarching objective of our study was to investigate curricular practices in accredited dietetics training programs in the U.S. including (1) the prevalence and perceived importance of vegetarian and vegan nutrition instruction and (2) if program directors connect vegetarian and vegan diets to climate change mitigation, resource conservation, and reducing impact on the natural environment. This understanding can delineate and bridge gaps in both dietetics education and dietetics practice. Hence, we investigated the curricular practices of Accreditation Council for Education in Nutrition and Dietetics (ACEND) programs in the U.S. ACEND is the accrediting agency of the Academy of Nutrition and Dietetics (23) while the U.S. Department of Education ensures that ACEND meets national standards (56).

In addition to our overarching research goals, we sought answers to numerous research questions including: the presence and type of barriers related to vegetarian and vegan diet instruction (if any); if a relationship exists amongst the characteristics of the university or program (e.g., region of the country, public, private, or religious affiliation, etc.); and the prevalence of vegetarian and vegan nutrition instruction or the associated connections between vegetarian and vegan diets and impact on the natural environment.

Programs accredited by ACEND encompass the educational and supervised practiced-based training experiences that prepare students for careers as dietitians or dietetic technicians (23). Didactic Programs in Dietetics (DPDs) are the undergraduate and graduate dietetics coursework completed before the dietetic internship (DI) which is a supervised practice experience completed after a baccalaureate or graduate degree. Coordinated Programs in Dietetics (CPDs) are undergraduate or graduate level dietetics coursework combined with the supervised practice experience. Dietetic technician programs offer a combined associate's degree and supervised practice experience (23).

\section{MATERIALS AND METHODS \\ Study Design and Participants}

This cross-sectional, Internet-based survey targeted all ACENDaccredited program directors listed on the ACEND website on July 19, 2017. International programs outside of U.S. territories were not included. This study was carried out in accordance with the recommendations of the University of Massachusetts Amherst Institutional Review Board with written informed consent from all subjects. All subjects gave written informed consent in accordance with the Declaration of Helsinki. The protocol was approved by the University of Massachusetts Amherst Institutional Review Board. Program directors represented CPD $n=61 \mid$ DI $n=257 \mid$ DPD $n=219 \mid$ and NDTRs $n=37$ for a total universe of $N=574$ programs. Two program directors were responsible for both a DI and a DPD and were instructed to complete one survey for each program if participating.

The target sample size was $n=231$ from a total universe of 574 ACEND-accredited programs. This target sample size was based on a $5 \%$ margin of error for a $95 \%$ confidence interval for population percentages. A (worst case) scenario of $50 \%$ for population percentages was assumed. In fact, the achieved sample size was $n=205$, somewhat less than the target of 231. As a consequence, the margin of error for population percentages varied from a low of $4 \%$ (when the sample percentage was small or was large) to $5.5 \%$ (when the sample percentage was close to $50 \%)$.

We were certainly aware of the possibility of non-response bias in our results. We were however, heartened by the fact that the mix of regions represented in our sample is a close match to the mix in the population of programs (Chi-square test of fit: $\left.X^{2}=0.73, p=0.867\right)$. Similarly, the mix of program types in our sample is a close match to the corresponding mix in the population (Chi-square test of fit: $X^{2}=0.3 .39, p=0.335$ ). Interestingly, some recent research is debunking the presumed relationship between survey response rates and the extent of non-response bias (57). 
FIGURE 1 | Examples of questions from the survey.

I. Questions eliciting the prevalence of vegetarian and vegan nutrition instruction and if a connection is made between vegetarian and vegan diets and climate change mitigation, resource conservation, or otherwise reducing impact on the natural environment

Is vegetarian nutrition formally taught in your program?

$\square$ Yes

$\square$ No: Proceed to question $x x$

$\square$ I don't know: Proceed to question xx

Is vegan nutrition taught in your program?

$\square$ Yes

$\square$ No: Proceed to question $x x$

$\square$ I don't know: Proceed to question xx

Does your program identify the connections between vegetarian and vegan diets in climate change mitigation, resource conservation, or otherwise

reducing impact on the natural environment?

$\square$ Yes

$\square$ No; Proceed to question $x x$

$\square$ I don't know: Proceed to question xx

To your knowledge, are there any dietetics faculty members that are

vegetarian or vegan?

$\square$ Yes

$\square$ No: Proceed to question xx

$\square$ I don't know: Proceed to question xx

II. Questions eliciting personal beliefs

To what extent do you believe that vegetarian nutrition should be taught in

accredited dietetics education programs?

$\square$ Strongly agree

$\square$ Agree

$\square$ Unsure

$\square$ Disagree

$\square$ Strongly disagree

To what extent do you believe that vegan nutrition should be taught in

accredited dietetics education programs?

$\square$ Strongly agree

$\square$ Agree

$\square$ Unsure

$\square$ Disagree

$\square$ Strongly disagree

How would you rate students' attitudes toward vegetarian and vegan diets?

$\square$ Highly acceptable

$\square$ Acceptable

$\square$ Unsure

$\square$ Unacceptable

$\square$ Highly unacceptable

III. Questions eliciting perceived barriers

Do you perceive barriers (if at all) in addressing vegetarian nutrition in

your program?

$\square$ Yes

$\square$ No; proceed to question $x x$

If yes, please check all that apply:

$\square$ Lack of interest among staff

$\square$ Knowledge deficits among staff

$\square$ Lack of interest among students

$\square$ Time constraints

Other (please explain):

Do you perceive barriers (if at all) in addressing vegan nutrition in

your program?

$\square$ Yes

$\square$ No; proceed to the end of the survey

If yes, please check all that apply:

$\square$ Lack of interest among staff

$\square$ Knowledge deficits among staff

$\square$ Lack of interest among students

$\square$ Time constraints

Other (please explain):

\section{Data Collection}

The survey included 37 questions that captured demographic data along with nominal and ordinal questions. An excerpt of our survey is included in Figure 1. As a first-time exploratory study, we could not locate a valid and reliable survey tool that addressed our research goals and questions. Similar to other important exploratory studies that connect seemingly disparate areas of healthcare and public health practice to environmental care $(58,59)$, we devised our survey tool with carefully planned steps and procedures. First, an informal pilot survey conducted in 2015 critically informed the content of this research study. From there, survey questions were developed in accordance with our research goals and were designed to elicit answers to our research questions. Our survey was then piloted and tested for face validity among seven $(n=7)$ dietetics educators and reviewed extensively by our research team. When revisions were recommended, they were discussed among our research team, tested again, and were then incorporated into the final survey.

The survey was administered online using the SurveyMonkey (San Mateo, CA) research service. Program directors were invited to participate via an email with the subject line entitled, "Survey: Vegetarian and Vegan Nutrition in ACEND Programs" which included the consent form and a link to the survey. Upon providing informed consent, respondents had the option of answering or skipping questions as desired. Automatic skips were also used based on responses to previous questions. It was made clear that all data would remain confidential. Upon completion of the survey, respondents could enter a drawing for one of two $\$ 150$ checks offered as a gesture of gratitude for their time and efforts. The survey was designed to be completed within 15-30 min.

The survey ran from July 19, 2017 to October 13, 2017 (87 days). Due to the time of year that may be associated with summer and fall holidays coupled with the lower response rates noted amongst other national Internet-based surveys of RDNs in the U.S. (60-63), email reminders about the survey were sent weekly for the first 3 weeks and again at 7 and 8 weeks. Because the response rate was $<50 \%$ at the end of 8 weeks, a subset of randomly selected non-respondents received a reminder telephone call. We called forty (40) program directors selected using a random number generator from the list of nonrespondents. Contacting this subset of forty helped us understand if reminder phone calls were a worthwhile endeavor. Thirty-two (32) potential respondents did not answer and messages were left per our telephone script. None of these program directors responded to the survey. We did not leave a message at two (2) telephone numbers because it was not personal voicemail that corresponded with the respective program director's name. Five (5) program directors answered our call and said they would or would try to complete the survey. Of these, three (3) responded to our survey. There was one (1) wrong number. Because the response rate after the first round of reminder calls was low, this technique was discontinued.

\section{Data Analysis}

The survey data were analyzed using the software package Minitab 18 (College Station, PA). Descriptive statistics involved 
TABLE 1 | ACEND-accredited program response rate per type and number of programs in the U.S.

\begin{tabular}{|c|c|c|c|c|}
\hline Type of ACEND program & $\begin{array}{c}\text { Number of } \\
\text { programs in } 2017\end{array}$ & $\begin{array}{l}\text { Number of } \\
\text { responses }\end{array}$ & $\begin{array}{c}\text { Response rate }(\%) \text { per } \\
\text { program type }\end{array}$ & $\begin{array}{l}\text { Percentage of } \\
\text { sample (\%) }\end{array}$ \\
\hline Coordinated Program in Dietetics (CPD) & 56 & 15 & 26.8 & 7.4 \\
\hline Dietetic Internship (DI) & 249 & 97 & 38.9 & 47.6 \\
\hline Didactic Program in Dietetics (DPD) & 223 & 82 & 36.7 & 40.2 \\
\hline Dietetic Technician Program (NDTR) & 42 & 10 & 23.8 & 4.9 \\
\hline
\end{tabular}

TABLE 2 | States with 10 or more responses.

\begin{tabular}{lccc}
\hline State & $\begin{array}{c}\text { Number of } \\
\text { responses }\end{array}$ & $\begin{array}{c}\text { Number of } \\
\text { programs in } \\
\text { that state }\end{array}$ & $\begin{array}{c}\text { Percentage of respondents } \\
\text { per number of programs in } \\
\text { the state }\end{array}$ \\
\hline California & 18 & 45 & 40.0 \\
Illinois & 12 & 26 & 46.2 \\
New York & 15 & 39 & 38.5 \\
Ohio & 13 & 35 & 37.1 \\
Pennsylvania & 10 & 26 & 38.5 \\
Texas & 18 & 44 & 40.9 \\
\hline
\end{tabular}

almost exclusively cross-tabulations. Inference methods were the chi-square test for independence and logistic regression. Only non-missing data was used and statistical significance was identified as a $p$-value equal to or $<0.05$. U.S. Census Bureau demarcation for region of the country (64) was used and programs outside the continental U.S. were coded as the South.

Our chi-square analysis examined if each of: (a) the prevalence of vegetarian and vegan nutrition instruction, (b) the belief that vegetarian and vegan nutrition should be taught, and (c) the connection between vegetarian and vegan diets and climate change and resource conservation varied significantly by (i) region of the country, (ii) type of ACEND-accredited program, (iii) ownership (public or private), or (iv) religious affiliation. Logistic regression was also used to examine if responses to the questions in (a), (b), and (c), above can be predicted from the variables ACEND-accredited program, region, ownership, and religious affiliation taken together.

Eighteen (18) questions offered the ability to write-in additional information as desired to prevent inadequate or missing information. Those responses were systematically categorized according to content. The results associated with these responses will be presented in a forthcoming publication specifically addressing curricular practices and demonstrated innovations in teaching vegetarian and vegan nutrition.

\section{Defining Vegetarian and Vegan Nutrition}

While derivations of the term "plant-based diet" are commonly used nowadays within the food industry, healthcare, and the dietetics profession not to mention among consumers nationwide, a practice-based definition as well as one that is recognized by the Academy of Nutrition has not been realized. Thus, we use the standard practice-based terms "vegetarian diet" and "vegan diet" to specify not only the nutritive components of the respective dietary pattern but to recognize the possibility of
TABLE 3 | Responses from programs with a religious affiliation.

\begin{tabular}{lc}
\hline Religion & Number of responses \\
\hline Baptist & 1 \\
Catholic & 13 \\
Church of Christ & 1 \\
Lutheran & 2 \\
Mormon & 2 \\
Nazarene & 2 \\
Presbyterian & 1 \\
Seventh-day Adventist & 3 \\
"Non-specific religious affiliation" & 1
\end{tabular}

nutrient deficiencies. A vegetarian diet was defined as a dietary pattern that is devoid of all flesh foods (meat, fowl, seafood, etc.) but may include eggs and dairy while a vegan diet was defined as dietary pattern devoid of all flesh foods as well as eggs, dairy, and other animal products (7).

\section{RESULTS}

The overall response rate was $36 \%$ with $n=205$ program directors participating ( $N=574$ programs). DI programs ( $n=97$ ) encompassed the largest percentage $(48 \%)$ of those responding to the survey; they also represent the largest number of ACEND-accredited programs. Table 1 shows the response rate among program types and the number of programs in the U.S. in 2017 whereas Table 2 shows the states that offered the greatest number of responses. Those five states comprise $\sim 37 \%$ of programs in the U.S. Nearly $75 \%$ of respondents represented public institutions. Of those from private institutions $(n=51)$, $12 \%$ had a religious affiliation that are listed in Table 3.

Over $51 \%(n=105)$ of respondents state that vegetarian nutrition is taught. There was a significant difference ( $p=0.00005)$ between the type of ACEND-accredited program and prevalence of teaching vegetarian nutrition, as indicated in Table 4. Vegetarian nutrition was taught in $80 \%$ of NDTR programs and in $\sim 25 \%$ of DIs. When vegetarian nutrition is not taught, nearly $77 \%$ of respondents offer resources for students as needed for patient care and other circumstances.

Almost $49 \%$ of program directors state that vegan nutrition is taught. However, the percentage indicating that vegan nutrition was taught varied significantly between type of ACENDaccredited programs $(p=0.00005)$ as indicated in Table 5. For example, $90 \%$ of NDTR programs indicate that they 
TABLE 4 | The prevalence of vegetarian nutrition instruction in ACEND programs.

\begin{tabular}{|c|c|c|c|c|c|}
\hline Prevalence & CPD & DPD & DI & NDTR & All \\
\hline Percentage responding "yes" to teaching & $73.3 \%$ & $75.6 \%$ & $24.7 \%$ & $80.0 \%$ & $51.5 \%$ \\
\hline vegetarian nutrition & $(11 / 15)$ & $(62 / 82)$ & $(24 / 97)$ & $(8 / 10)$ & $(105 / 204)$ \\
\hline
\end{tabular}

$X^{2}=53.0, p<0.00005$

TABLE 5 | The prevalence of vegan nutrition instruction in ACEND programs.

\begin{tabular}{|c|c|c|c|c|c|}
\hline Prevalence & CPD & DPD & DI & NDTR & All \\
\hline Percentage responding "yes" to teaching & $73.3 \%$ & $70.9 \%$ & $22.6 \%$ & $90.0 \%$ & $49.2 \%$ \\
\hline vegan nutrition & $(11 / 15)$ & (56/79) & $(21 / 93)$ & $(9 / 10)$ & (97/197) \\
\hline
\end{tabular}

$X^{2}=51.4, p<0.00005$

teach vegan nutrition while only $23 \%$ of DI programs do. Beyond the statistically significant difference in prevalence of vegetarian and vegan nutrition instruction by program type, no other comparison (by region of country, program ownership, or religious affiliation) came remotely close to statistical significance.

Over $90 \%$ of program directors strongly agree (48\%) and agree (43\%) that vegetarian nutrition should be taught while nearly $44 \%$ strongly agree and $43 \%$ agree that vegan nutrition should be taught. Approximately $9 \%$ are unsure that either of these topics should be taught. Only one $(n=1)$ respondent disagreed that vegetarian and vegan nutrition should be taught. The percentage of respondents in the South $(75.4 \%)$ who strongly agree or agree that vegan nutrition should be taught is notably smaller than the corresponding percentages for Northeast programs (96.0\%), Midwest programs (88.6\%), and Western programs (93.3\%). These differences are statistically significant $(p=0.006)$.

Approximately $90 \%$ of program directors rate students' attitudes toward vegetarian and vegan diets as highly acceptable (36\%) and acceptable (53\%). Sixteen percent (16\%) of respondents perceive barriers in addressing vegetarian and vegan nutrition in their respective programs with $67 \%$ citing time constraints $(n=21)$. Four $(n=4)$ respondents $(\sim 13 \%)$ cite knowledge deficits among staff.

Nearly $58 \%$ of respondents indicate that there is a vegetarian or vegan faculty member in their respective program; however, almost $69 \%$ who responded affirmatively do not believe their presence influences the inclusion of vegetarian and vegan nutrition in their respective curriculums.

Fifty percent $(50 \%)$ of respondents $(n=93)$ identify the connections between vegetarian and vegan diets in climate change mitigation, resource conservation, and reducing impact on the natural environment while nearly $33 \%(n=61)$ do not and nearly $17 \%$ are unsure.

\section{DISCUSSION}

To our knowledge, this is first study published of the prevalence of vegetarian and vegan nutrition instruction across ACENDaccredited programs in the U.S. and the first account of dietetics program educators linking vegetarian and vegan diets to climate change mitigation, resource conservation, and reducing impact on the natural environment. Several important findings follow from the study: (1) More than $90 \%$ of program directors that responded agree that vegetarian and vegan nutrition should be taught and perceive that students' attitudes toward vegetarian and vegan diets are favorable; (2) over half of programs (51\%) teach vegetarian nutrition while slightly less (49\%) teach vegan nutrition; (3) significant differences exist between the type of ACEND-accredited program and the prevalence of vegetarian $(p=0.00005)$ and vegan $(p=0.00005)$ nutrition instruction, respectively; (4) over $50 \%$ of programs connect vegetarian and vegan diets to climate change mitigation, resource conservation, and reducing impact on the natural environment; (5) region of the country $(p=0.006)$ impacted program directors' belief that vegan nutrition should be taught $(p=0.006)$.

It is clear that program directors support vegetarian and vegan nutrition instruction and perceive that students are also interested. This is reassuring given the burgeoning array of evidenced-based data that demonstrate the human health benefits of vegetarian and vegan dietary patterns, the benefits of diets high in fiber and nutrient-dense whole plant foods, and the concurrent positive impact on the natural environment. Overall, however, there appear to be discrepancies between enthusiasm for vegetarian and vegan diet instruction and incorporating these topics into dietetics education and training. Interestingly, most respondents did not perceive barriers in addressing vegetarian and vegan nutrition in their respective program.

While the literature is altogether insufficient with regard to data on incorporating vegetarian and vegan nutrition into dietetics education and training programs, the results of this study offer a compelling reason to formally include vegetarian and vegan nutrition training in accredited dietetics programs. Hence, the Vegetarian Nutrition (VN) Dietetic Practice Group (DPG) (65) of The Academy of Nutrition and Dietetics could be an invaluable asset in this realm, identifying the needs of ACEND-accredited program directors and offering resources that could increase self-efficacy among program directors and students while advancing the dietetics profession. Dietetic practice groups (DPG's) are professional interest groups of the Academy of Nutrition and Dietetics where a wealth of knowledge and skill about a distinct topic is shared among members (66). 
Additionally, the Academy of Nutrition and Dietetics' Vegetarian Nutrition Certification Program could prove invaluable (67).

The type of ACEND-accredited program predicts agreement that vegetarian nutrition instruction should be taught $(p=0.010)$. This may be due to differences in the perception of vegetarian nutrition as "foundational" knowledge as would be the case in DPD, CPD, and NDTR programs compared to a perception of the "applied" knowledge of DIs. The ACEND Accreditation Standards do not mandate vegetarian and vegan nutrition instruction as a requirement but do mandate competencies for health promotion and disease prevention that would encompass vegetarian and vegan diet instruction. For instance, there are mandates that the student would demonstrate competencies that "Develop and deliver products, programs or services that promote consumer health, wellness and lifestyle management" (68). Because of the preventive and therapeutic role of vegetarian and vegan diets in human health, mandating vegetarian and vegan diet training requirements by ACEND is advised. Furthermore, as plant-based foods are leading foodservice trends and meatless meals are becoming increasingly prevalent in food service establishments including healthcare and correctional facilities (69) and schools, mandatory vegetarian and vegan nutrition training for dietetics students that can be applied across population groups and ethnicities would better serve the needs of the general public and industry.

Because of the varying routes of education and training and the multitude of diverse populations served during the applied training experiences-there is no "one size fits all" approach to teaching and promoting vegetarian and vegan diets in practice. Our results suggesting that DIs have the lowest prevalence of vegetarian and vegan nutrition instruction deserves special attention. DIs comprise an important route of dietetics training and are based on competency requirements vs. the core knowledge and competency requirements of supervised practice programs (70). The DI is an invaluable applied training experience where dietetic interns could utilize vegetarian and vegan dietary principles in a multitude of ways such as direct patient care, rotations in public health and foodservice, cooking demonstrations, health promotion, or research. While students may come to their DI with textbook knowledge of vegetarian and vegan diets, formal instruction on applying vegetarian and vegan diets during the DI could improve patient outcomes and is therefore advisable.

Climate change mitigation goals will not be met without substantial adherence to plant-based consumption patterns (42), and $50 \%$ of respondents identify that their program connects the use of vegetarian and vegan diets in climate change mitigation, resource conservation, and reduced environmental impact. Given the ACEND curriculum mandate (starting July $1,2017)$ that dietetics students "propose and use procedures as appropriate to the practice setting to promote sustainability, reduce waste and protect the environment," (68) it is concerning that only $50 \%$ of program directors connect vegetarian and vegan diets to climate change mitigation, resource conservation, and reduced environmental impact.

Other studies identify similar trends. Webber and Sarjahani's (53) study of DI programs found that nearly $50 \%$ of directors either included content related to sustainable food systems or planned to (53). A 2011 survey of nutrition educators in dietetic training programs found that only $42 \%$ of respondents stated confidence in teaching the concepts of sustainable food systems (50). A lack of self-efficacy appears to be a barrier in teaching sustainable food systems in dietetics education (50) while inconsistent connections between diet and sustainability in training programs affects practice-based behaviors. For example, a 2017 survey of dietitians found that only $47 \%$ incorporated principles of sustainable food systems into practice (71).

Hence, an opportunity exists for the Hunger and Environmental Nutrition (HEN) DPG and the VN DPG to collaborate and offer guidance to ACEND program directors that would increase self-efficacy and eliminate knowledge deficits in this area. HEN's mission is to, "Empower members to be leaders in sustainable and accessible food and water systems (72). Although both DPGs have advocated for plant-based diets to reduce environmental impact $(48,73)$, an opportunity exists to strengthen collaboration, outreach, and impact.

Increased self-efficacy with regard to vegetarian and vegan nutrition and sustainable food systems impacts practice behaviors. Vegetarian dietitians and vegan dietitians were significantly more likely than non-vegetarian and non-vegan dietitians to use diet as a climate change mitigation strategy in practice, likely due to high levels of self-efficacy by virtue of the lived experience (30). Dietitians that engaged in the personal pro-environmental behaviors of (1) consuming organic foods (2) purchasing locally produced foods (3) consuming seasonal foods (4) growing produce and (5) composting food waste were significantly more likely to recommend the same behaviors in practice than those dietitians that do not engage in these behaviors $(74,75)$.

The percentage of program directors agreeing that vegan nutrition should be taught varied significantly by region of the country $(p=0.006)$; in particular, programs in the South agreed at notably smaller rates than the other three regions. Hawkins et al. found that dietitians residing in the South were significantly less likely to agree that climate change is an important issue than dietitians residing in other regions of the country (30). While these are separate issues, it points to regional differences among dietitians that are worthy of further exploration.

While over 200 program directors participated in this study, the results cannot be extrapolated to all program directors and settings. There are other limitations to consider. Those that completed this survey (36\%) may be different and more supportive of vegetarian and vegan nutrition than those that did not respond (64\%). It also could be that those that responded to the survey may have offered socially desirable responses.

In our survey, we used the terms vegetarian diets and vegan diets as they are defined in the evidenced-based literature and in dietetics practice (7). We could not locate research that clarifies how dietitians perceive the term "plant-based diet" which has not yet been defined in dietetics practice although it now used frequently the literature (76) and among the general public. Thus, it is unknown if we could we have garnered a higher response rate if framing our study with the term "plant-based diet" vs. vegetarian diet or vegan diet. 
We did not inquire if ACEND-accredited programs were land-grant universities and colleges which could have influenced our response rate or the responses we received altogether. Land-grant institutions receive support to both teach and research agriculture and that may include animal husbandry and dairying (77).

The response to our survey was slightly lower than anticipated. However, our response rate of $36 \%$ was higher than other national surveys of dietitians $(30,60-62,71)$. Our survey was initially sent in the summertime, which may have been a time where program directors were away from campus, on vacation, or contending with other program issues such as accreditation site visits. Although we were able to increase participation by way of reminder emails, we are not certain that all intended recipients received our email. Lastly, complimentary research methods such as focus groups could prove useful in future iterations of this research to expound upon the concepts of self-efficacy or the perceived knowledge deficits unveiled in this study.

\section{CONCLUSIONS}

Most directors of ACEND-accredited programs are in favor of teaching students about vegetarian and vegan nutrition and believe students are receptive to such instructions. Despite this, formal instruction occurs in approximately half of programs overall while only half of program directors connect vegetarian and vegan diets to reduced environmental impact. These results suggest the need for novel interventions such as creating curriculum mandates for vegetarian and vegan nutrition instruction and increasing self-efficacy related to connecting diet to environmental impact. Importantly, increased collaboration among dietetics professionals could correct these deficits.

\section{DATA AVAILABILITY}

The raw data supporting the conclusions of this manuscript will be made available by the authors, without undue reservation, to any qualified researcher.

\section{ETHICS STATEMENT}

This study was carried out in accordance with the recommendations of The University of Massachusetts Amherst Institutional Review Board with written informed consent from all subjects. All subjects gave written informed consent in accordance with the Declaration of Helsinki. The protocol was approved by the the University of Massachusetts Amherst Institutional Review Board.

\section{REFERENCES}

1. Murphy SL, Xu J, Kochanek KD, Curtin SC, Arias E. Deaths: final data for 2015. Natl Vital Stat Rep. (2017) 66:1-75.

2. Stokes A, Preston SH. Deaths attributable to diabetes in the United States: comparison of data sources and estimation approaches. PLOS ONE. (2017) 12:e0170219. doi: 10.1371/journal.pone.0170219

\section{AUTHOR CONTRIBUTIONS}

IH, AM, RG, and RW designed the survey. IH and AM collected the data. RG conducted the analysis with input from IH. IH and AM wrote the first draft with contributions from RG. All authors reviewed and commented on subsequent drafts of the manuscript.

\section{FUNDING}

This research was supported by the Academy of Nutrition and Dietetics Foundation Vegetarian Nutrition Dietetic Practice Group Research Grant.

\section{ACKNOWLEDGMENTS}

We gratefully acknowledge the funding and support of the Academy of Nutrition and Dietetics Foundation Vegetarian Nutrition Dietetic Practice Group Research Grant. The authors thank the survey respondents for their time and contributions; those educators that tested the face validity of our survey; and all reviewers that helped improve this paper. Special thanks is also extended to Dr. Alan Balsam, RDN, for offering critical insights upon reviewing our manuscript.

\section{PRACTICE IMPLICATIONS}

This is the first published study on the prevalence of vegetarian and vegan nutrition instruction in nationally-accredited dietetic programs in the U.S. Dietetic programs train future registered dietitian nutritionists and dietetic technicians. There is a strong connection between vegetarian and vegan diets and reduced risk of many nutrition-related chronic diseases. Additionally, these diets are associated with a reduced environmental impact. Despite this strong diet-disease and diet-environment connection, prior to this study, it was not known if dietetics students are taught the principles of vegetarian and vegan nutrition. This research provides information on both program directors' support for the inclusion of vegetarian and vegan nutrition instruction while demonstrating a gap between beliefs and practice behaviors. In an era of environmental concern, half connect use of a vegetarian or vegan diet to reduced environmental degradation. Using novel techniques and improved collaboration to increase the prevalence of vegetarian and vegan nutrition instruction and its application in dietetics training could better prepare Registered Dietitian Nutritionists and Dietetic Technicians to improve both individual health and planetary health outcomes. 
5. Centers for Disease Control and Prevention. National Diabetes Statistics Report, 2017. Atlanta, GA: Centers for Disease Control and Prevention, US Department of Health and Human Services (2017). p. 20.

6. World Cancer Research Fund/American Institute for Cancer Research. Diet, Nutrition, Physical Activity and Cancer: A Global Perspective. Continuous Update Project Expert Report 2018. World Cancer Research Fund/American Institute for Cancer Research (2018). Available online at: http://dietandcancerreport.org (accessed September 5, 2018).

7. Melina V, Craig W, Levin S. Position of the Academy of Nutrition and Dietetics: Vegetarian diets. J Am Diet Assoc. (2016) 116:197080. doi: 10.1016/j.jand.2016.09.025

8. Yokoyama Y, Nishimura K, Barnard ND, Takegami M, Watanabe M, Sekikawa A, et al. Vegetarian diets and blood pressure: a meta-analysis. JAMA Intern Med. (2014) 174:577-87. doi: 10.1001/jamainternmed.2013.14547

9. Dinu M, Abbate R, Gensini GF, Casini A, Sofi F. Vegetarian, vegan diets and multiple health outcomes: a systematic review with metaanalysis of observational studies. Crit Rev Food Sci Nutr. (2017) 57:36409. doi: 10.1080/10408398.2016.1138447

10. Huang T, Yang B, Zheng J, Li G, Wahlqvist ML, Li D. Cardiovascular disease mortality and cancer incidence in vegetarians: a meta-analysis and systematic review. Ann Nutr Metab. (2012) 60:233-40. doi: 10.1109/TCOMM.2012.01.cover3

11. Tonstad S, Butler T, Yan R, Fraser GE. Type of vegetarian diet, body weight, and prevalence of type 2 diabetes. Diabetes Care. (2009) 32:7916. doi: $10.2337 / \mathrm{dc} 08-1886$

12. Pettersen BJ, Anousheh R, Fan J, Jaceldo-Siegl K, Fraser GE. Vegetarian diets and blood pressure among white subjects: results from the Adventist Health Study-2 (AHS-2). Public Health Nutr. (2012) 15:1909-16. doi: 10.1017/S1368980011003454

13. Yokoyama Y, Barnard ND, Levin SM, Watanabe M. Vegetarian diets and glycemic control in diabetes: a systematic review and meta-analysis. Cardiovasc Diagn Ther. (2014) 4:37382. doi: 10.3978/j.issn.2223-3652.2014.10.04

14. Viguiliouk E, Kendall CW, Kahleová H, Rahelić D, Salas-Salvadó J, Choo VL, et al. Effect of vegetarian dietary patterns on cardiometabolic risk factors in diabetes: a systematic review and meta-analysis of randomized controlled trials. Clin Nutr. (2019) 38:1133-45. doi: 10.1016/j.clnu.2018.05.032

15. Huang RY, Huang CC, Hu FB, Chavarro JE. Vegetarian diets and weight reduction: a meta-analysis of randomized controlled trials. J Gen Intern Med. (2016) 31:109-16. doi: 10.1007/s11606-015-3390-7

16. Zhang YJ, Gan RY, Li S, Zhou Y, Li AN, Xu DP, et al. Antioxidant phytochemicals for the prevention and treatment of chronic diseases. Molecules. (2015) 20:21138-56. doi: 10.3390/molecules201219753

17. Ahluwalia A, Gladwin M, Coleman GD, Hord N, Howard G, Kim DB, et al. Dietary nitrate and the epidemiology of cardiovascular disease: Report from a National Heart, Lung, and Blood Institute workshop. J Am Heart Assoc. (2016) 5:e003402. doi: 10.1161/JAHA.116.003402

18. Dahl WJ, Stewart ML. Position of the Academy of Nutrition and Dietetics: Health implications of dietary fiber. J Acad Nutr Diet. (2015) 115:186170. doi: 10.1016/j.jand.2015.09.003

19. US Department of Health and Human Services, U.S. Department of Agriculture. 2015 - 2020 Dietary Guidelines for Americans. 8th ed. Health.gov (2015). Available online at: https://health.gov/dietaryguidelines/ 2015/guidelines/ (accessed March 5, 2019).

20. Bouvard V, Loomis D, Guyton KZ, Grosse Y, Ghissassi FE, Benbrahim-Tallaa L, et al. Carcinogenicity of consumption of red and processed meat. Lancet Oncol. (2015) 16:1599-600. doi: 10.1016/S1470-2045(15)00444-1

21. Wang $\mathrm{X}$, Lin $\mathrm{X}$, Ouyang $\mathrm{YY}$, Liu J, Zhao G, Pan A, et al. Red and processed meat consumption and mortality: dose-response metaanalysis of prospective cohort studies. Public Health Nutr. (2016) 19:893905. doi: 10.1017/S1368980015002062

22. Pan A, Sun, Q, Bernstein AM, Manson JE, Willett WC, Hu FB. Changes in red meat consumption and subsequent risk of type 2 diabetes mellitus: three cohorts of US men and women. JAMA Intern Med. (2013) 173:132835. doi: 10.1001/jamainternmed.2013.6633

23. Accreditation Council for Education in Nutrition and Dietetics. Accredited Dietetics Education Programs. ACEND. Available online at: https://www. eatrightpro.org/acend/accredited-programs/about-accredited-programs (accessed September 6, 2018).

24. Academy of Nutrition and Dietetics, Commission on Dietetic Registration. Code of Ethics for the Nutrition and Dietetics Professional. Available online at: https://www.eatrightpro.org/-/media/eatrightpro-files/career/ code-of-ethics/coeforthenutritionanddieteticsprofession.pdf?la=en\&hash= 0C9D1622C51782F12A0D6004A28CDAC0CE99A032 (accessed July 2, 2019).

25. Hughes GJ, Kress KS, Armbrecht ES, Mukherjea R Mattfeldt-Beman M. Initial investigation of dietitian perception of plant-based protein quality. Food Sci Nutr. (2014) 2:371-9. doi: 10.1002/fsn3.112

26. Lee V, McKay T, Ardern CI. Awareness and perception of plantbased diets for the treatment and management of type 2 diabetes in a community education clinic: a pilot study. J Nutr Metab. (2015) 2015:236234. doi: 10.1155/2015/236234

27. Bandura A. Self-efficacy: toward a unifying theory of behavioral change. Psychol Rev. (1977) 84:191-215. doi: 10.1037//0033-295X.84.2.191

28. Bandura A. Perceived self-efficacy in cognitive development and functioning. Educ Psychol. (1993) 28:117-48. doi: 10.1207/s15326985ep2802_3

29. Hawkins IW, Balsam AL, Graves D. A qualitative study of the skills that enabled the pro-environmental behaviors of registered dietitians. J Hunger Environ Nutr. (2015) 10:60-71. doi: 10.1080/19320248.2014.929546

30. Hawkins IW, Balsam AL, Goldman R. A survey of registered dietitians' concern and actions regarding climate change in the United States. Front Nutr. (2015) 2:21. doi: 10.3389/fnut.2015.00021

31. Steffen W, Rockström J, Richardson K, Lenton TM, Folke C, Liverman D, et al. Trajectories of the Earth System in the Anthropocene. Proc Natl Acad Sci USA. (2018) 115:8252-9. doi: 10.1073/pnas.1810141115

32. Global Footprint Network. Past Earth Overshoot Days. Available online at: https://www.overshootday.org/newsroom/past-earth-overshoot-days/ (accessed July 2, 2019).

33. Steffen W, Richardson K, Rockström J, Cornell SE, Fetzer I, Bennet EM, et al. Sustainability: planetary boundaries: guiding human development on a changing planet. Science. (2015) 347:1259855. doi: 10.1126/science. 1259855

34. Ceballos G, Ehrlich PR, Dirzo R. Biological annihilation via the ongoing sixth mass extinction signaled by vertebrate population losses and declines. Proc Natl Acad Sci USA. (2017) 114:E6089-96. doi: 10.1073/pnas.1704949114

35. IPBES Summary for Policymakers of the Assessment Report of the Intergovernmental Science-Policy Platform on Biodiversity and Ecosystem Services on Pollinators, Pollination and Food Production. (2019). Available online at: https://www.ipbes.net/system/tdf/spm_deliverable_3a_pollination_ 20170222.pdf?file=1\&type=node\&id=15248 (accessed July 2, 2019).

36. IPBES. The IPBES Presents the Latest UN Science Report on Global Biodiversity Assessment. (2019). Available online at: https://www.youtube.com/watch?v= d3QdVxExI4U (accessed July 2, 2019).

37. Tilma n D, Clark M. Global diets link environmental sustainability and human health. Nature. (2014) 515:518-22. doi: 10.1038/nature13959

38. Soret S, Mejia A, Batech M, Jaceldo-Siegl K, Harwatt H, Sabaté J. Climate change mitigation and health effects of varied dietary patterns in real-life settings throughout North America. Am J Clin Nutr. (2014) 100(Suppl. 1):476S-82S. doi: 10.3945/ajcn.113.071589

39. Springmann M, Wiebe K, Mason-D'Croz D, Sulser TB, Rayner M, Scarborough S. Health and nutritional aspects of sustainable diet strategies and their association with environmental impacts: a global modelling analysis with country-level detail. Lancet Planetary Health. (2018) 2:e45161. doi: 10.1016/S2542-5196(18)30206-7

40. Springmann M, Godfray HCJ, Rayner M, Scarborough P. Analysis and valuation of the health and climate change cobenefits of dietary change. Proc Natl Acad Sci USA. (2016) 113:4146-51. doi: 10.1073/pnas.1523119113

41. Scarborough P, Appleby PN, Mizdrak A, Briggs AD, Travis RC, Bradbury $\mathrm{KE}$, et al. Dietary greenhouse gas emissions of meateaters, fish-eaters, vegetarians and vegans in the UK. Clim Change. (2014) 125:17992. doi: 10.1007/s10584-014-1169-1

42. Hedenus F, Wirsenius S, Johansson DJA. The importance of reduced meat and dairy consumption for meeting stringent climate change targets. Clim Change. (2014) 124:79-91. doi: 10.1007/s10584-014-1104-5 
43. Pelletier N, Tyedmers P. Forecasting potential global environmental costs of livestock production 2000-2050. Proc Natl Acad Sci USA. (2010) 107:183714. doi: $10.1073 /$ pnas. 1004659107

44. Shepon A, Gidon E, Noor E, Milo R. The opportunity cost of animal based diets exceeds all food losses. Proc Natl Acad Sci USA. (2018) 115:38049. doi: 10.1073/pnas.1713820115

45. Willett W, Rockström J, Loken B, Springmann M, Lang T, Vermeulen $\mathrm{S}$, et al. Food in the Anthropocene: the EAT-Lancet Commission on healthy diets from sustainable food systems. Lancet. (2019) 393:44792. doi: 10.1016/S0140-6736(18)31788-4

46. The EAT-Lancet Commission on Food, Planet, and Health. Summary Report. Healthy Diets from Sustainable Food Systems. (2019). Available online at: https://eatforum.org/content/uploads/2019/04/EAT-Lancet_Commission_ Summary_Report.pdf (accessed July 4, 2019).

47. Tagtow A, Harmon A. Healthy Land, Healthy Food \& Healthy Eaters. (2008). Available online at: http://www.uwyo.edu/winwyoming/pubs/healthyland \%20healthyfood\%20healthyeaters.pdf (accessed July 1, 2019).

48. Harmon AH, Gerard, BL, American Dietetic Association. Position of the American Dietetic Association: food and nutrition professionals can implement practices to conserve natural resources and support ecological sustainability. J Am Diet Assoc. (2007) 107:1033-43. doi: 10.1016/j.jada.2007.04.018

49. Robinson-O'Brien R, Gerald BL. Practice Paper of the Academy of Nutrition and Dietetics: promoting ecological sustainability within the food system. $J$ Acad Nutr Diet. (2013) 113:464. doi: 10.1016/j.jand.2013.01.016

50. Hawkins IW, editor. Promoting Biodiversity in Food Systems. Boca Raton, FL: CRC Press (2019).

51. Tagtow A, Robien K, Bergquist E, Bruening M, Dierks L, Hartman BE, et al. Academy of Nutrition and Dietetics: Standards of professional performance for Registered Dietitian Nutritionists (Competent, Proficient, and Expert) in Sustainable, Resilient, and Healthy Food and Water Systems. J Acad Nutr Diet. (2014)114:475-88. doi: 10.1016/j.jand.2013.11.011

52. Harmon A, Lapp JL, Blair D, Hauck-Lawson A. Teaching food system sustainability in dietetic programs: need, conceptualization, and practical approaches. J Hunger Environ Nutr. (2011) 6:114-24. doi: 10.1080/19320248.2011.554272

53. Webber CB, Sarjahani A. Fitting sustainable food systems into dietetic internships-a growing trend. J Hunger Environ Nutr. (2011) 6:47789. doi: $10.1080 / 19320248.2011 .627304$

54. West Chester University. Nutrition. Available online at: https://www.wcupa. edu/healthSciences/nutritionAndDietetics/ (accessed 2019 July 2).

55. Veidis EM, Myers SS, Almada AA, Golden CD; Clinicians for Planetary Health Working Group. A call for clinicians to act on planetary health. Lancet. (2019) 393:2021. doi: 10.1016/S0140-6736(19)30846-3

56. Accreditation Council for Education in Nutrition and Dietetics. ACEND. ACEND. Available online at: https://www.eatrightpro.org/acend (accessed March 9, 2019).

57. Hendra R, Hill A. Rethinking response rates: new evidence of little relationship between survey response rates and nonresponse bias. Eval Rev. (2018) 1-24. doi: 10.1177/0193841X18807719

58. Polivka BJ, Chaudry RV, Crawford JM. Public health nurses' knowledge and attitudes regarding climate change. Environ Health Perspect. (2012) 120:3215. doi: 10.1289/ehp.1104025

59. Truckner RT. Health care provider beliefs concerning the adverse health effects of environmental ecosystem degradation. Wilderness Environ Med. (2009) 20:199-211. doi: 10.1580/08-WEME-OR-222R1.1

60. Ayres EJ, Hoggle LB. ADA Nutrition Informatics member survey: results and future steps. J Am Diet Assoc. (2008) 108:18246. doi: 10.1016/j.jada.2008.09.016

61. Dickinson A, Bonci L, Boyon N, Franco JC. Dietitians use and recommend dietary supplements: report of a survey. Nutr J. (2012) 11:14. doi: 10.1186/1475-2891-11-14

62. Grace-Farfaglia P, Pickett-Bernard D, White Gorman A, Dehpahlavan J. Health philosophy of dietitians and its implications for life satisfaction: an exploratory study. Behav Sci. (2017) 7:E67. doi: 10.3390/ bs7040067
63. Hand RK, Burrowes JD. Renal dietitians' perceptions of roles and responsibilities in outpatient dialysis facilities. J Ren Nutr. (2015) 25:40411. doi: $10.1053 /$ j.jrn.2015.04.008

64. U.S. Census Bureau. Census Bureau Regions and Divisions with State FIPS Codes. U.S. Census Bureau. Available online at: https://www2.census.gov/geo/ pdfs/maps-data/maps/reference/us_regdiv.pdf (accessed July 20, 2018).

65. Academy of Nutrition and Dietetics. Vegetarian Nutrition DPG. Academy of Nutrition and Dietetics. Available online at: https://www.eatrightpro. org/membership/academy-groups/dietetic-practice-groups/vegetariannutrition-dpg (accessed September 6, 2018).

66. Academy of Nutrition and Dietetics. Dietetic Practice Groups. Academy of Nutrition and Dietetics. Available online at: https://www.eatrightpro.org/ membership/academy-groups/dietetic-practice-groups (accessed September 6, 2018).

67. Eat Right Store Academy of Nutrition and Dietetics. Vegetarian Nutrition Training Module. Available online at: https://www.eatrightstore.org/ collections/vegetarian-nutrition?_ga $=2.73649362 .1383987596 .1561666884-$ 466145732.1561226994 (accessed July 2, 2019).

68. ACEND Accreditation Standards for Nutrition and Dietetics Internship Programs (DI) Adopted July 29, 2016. Available online at: https:// www.eatrightpro.org/-/media/eatrightpro-files/acend/about-programaccreditation/accreditation-standards/2017-standardsfordiprograms.pdf?la= en\&hash=B1F08833AABC0FA8A6EBB7B76778A09BE7EDB667 (accessed July 2, 2019).

69. California Legislative Information. California State Legislature. Senate Bill No. 1138. CHAPTER 512. Food Options: Plant-Based Meals. Available online at: https://leginfo.legislature.ca.gov/faces/billTextClient.xhtml?bill_id= 201720180SB1138 (accessed July 2, 2019).

70. Commission on Dietetic Registration. Course: Dietetics Preceptor Training Program- Modules 1-7. Commission on Dietetic Registration. Available online at: https://www.cdrcampus.com/course/view.php?id=131\&page $=1554$ (accessed December 1, 2018).

71. Heidelberger L, Smith C, Robinson-O'Brien R, Earthman C, Robien K. Registered Dietitian Nutritionists' perspectives on integrating food and water system issues into professional practice. J Acad Nutr Diet. (2017) 117:2717. doi: $10.1016 / j . j$ jand.2016.06.380

72. Hunger and Environmental Nutrition Dietetic Practice Group. The Academy of Nutrition and Dietetics. Available online at: https://hendpg.org/about-us (accessed July 4, 2019).

73. Hawkins IW. Registered Dietitian Resource for Professionals: Plant-Based Diets in Climate Change Mitigation and Resource Conservation. Vegetarian Nutrition Dietetic Practice Group/Academy of Nutrition and Dietetics (2015) Available online at: https://vndpg.org/wp-content/uploads/2015/02/ClimateChange-RD.pdf (accessed July 2, 2019).

74. Hawkins IW. Registered dietitians' concern and actions regarding climate change. (Ph.D. dissertation), Simmons College (2013).

75. Hawkins IW. Dietetics: at the root of good health. ANDID Notizie. J Ital Natl Assoc Dietit. (2016) 6:20-3.

76. Hever J. Plant-based diets: a physician's guide. Perm J. (2016) 20:1582. doi: 10.7812/TPP/15-082

77. Association of Public and Land-Grant Universities. The Land-Grant Tradition. Association of Public and Land-Grant Universities (2012) Available online at: http://www.aplu.org/library/the-land-grant-tradition/file (accessed September 6, 2018).

Conflict of Interest Statement: The authors declare that the research was conducted in the absence of any commercial or financial relationships that could be construed as a potential conflict of interest.

Copyright $\odot 2019$ Hawkins, Mangels, Goldman and Wood. This is an open-access article distributed under the terms of the Creative Commons Attribution License (CC $B Y)$. The use, distribution or reproduction in other forums is permitted, provided the original author(s) and the copyright owner(s) are credited and that the original publication in this journal is cited, in accordance with accepted academic practice. No use, distribution or reproduction is permitted which does not comply with these terms. 